\title{
PRODUTIVIDADE E QUALIDADE DE TUBÉRCULOS DE BATATA EM FUNÇÃO DO FERTILIZANTE ORGANOMINERAL E SAFRAS DE PLANTIO ${ }^{1}$
}

\author{
ATALITA FRANCIS CARDOSO ${ }^{2 *}$, JOSÉ MAGNO QUEIROZ LUZ ${ }^{3}$, REGINA MARIA QUINTÃO LANA ${ }^{4}$
}

\begin{abstract}
RESUMO - O objetivo deste estudo foi avaliar a produtividade e a qualidade dos tubérculos da batateira em função da redução das doses do fertilizante organomineral em diferentes safras de plantio. Os experimentos foram conduzidos em Cristalina-Goiás nas safras de inverno (2013) e das águas (2013/2014). O delineamento experimental foi em blocos ao acaso, com 6 doses e 4 repetições na safra de inverno, totalizando 24 parcelas. $\mathrm{Na}$ safra das águas o experimento constituiu de 7 doses e 4 repetições, totalizando 28 parcelas. As doses de organomineral foram fixadas de acordo com a recomendação mediante análise do solo para fertilizante mineral. As doses testadas foram: $2800 \mathrm{~kg} \mathrm{ha}^{-1}$ do formulado 3-32-6; 1629,10;2443,60; 4072,70; e 4887,30 kg ha' do fertilizante organomineral correspondente a 40,60, 80, 100 e $120 \%$ da dose de fertilizante mineral. Na safra das águas foi incluído um tratamento testemunha (sem adubação). Os fertilizantes organomineral e mineral foram aplicados em sulco de plantio. Aos $30 \mathrm{DAP}$, na safra de inverno, foram acrescidos $300 \mathrm{~kg} \mathrm{ha}^{-1}$ do formulado 20 -00-20, em cobertura. A produtividade e classificação dos tubérculos foram estimadas na massa fresca e no diâmetro dos tubérculos, respectivamente. Os resultados obtidos na safra de inverno foram superiores para todas as características avaliadas. A dose $4072,70 \mathrm{~kg} \mathrm{ha}^{-1}$ de organomineral equivalente a $100 \%$ da dose mineral proporcionou maior produtividade e melhor qualidade de tubérculos nas safras avaliadas. Em relação ao teor de sólidos solúveis, a safra de inverno apresentou resultados mais satisfatórios.
\end{abstract}

Palavras-chave: Solanum tuberosum. Nutrição. Organominerais.

\section{PRODUCTIVITY OF POTATO TUBERS “ATLANTIC" AS A FUNCTION OF ORGANOMINERAL FERTILIZER USE}

\begin{abstract}
The study evaluated potato tuber yield and quality, using cultivar Atlantic, as a function of organomineral fertilizer doses applied in the planting furrow. The experiments were done in Cristalina, Goiás, in winter and summer cultive. The experimental design was randomized blocks, with six doses in the winter experiment and seven doses in the summer one, both with four replications. The doses were fixed according to the recommendation for mineral fertilizer. The doses evaluated were $2800 \mathrm{~kg} \mathrm{ha}^{-1}$ of formulation 3-32-6, $1629.10,2443.60,4072.70$ and $4887.30 \mathrm{~kg} \mathrm{ha}^{-1}$ of organomineral fertilizer, corresponding to 40,60, 80, 100 and $120 \%$ of the mineral fertilizer dose. A treatment with no fertilizer (control) was included in the summer experiment. Fertilizers were applied in the planting furrow. Side dressing fertilization was done 30 DAP, in winter crop, with $300 \mathrm{~kg} \mathrm{ha}^{-1}$ of formulation 20-00-20. Tubers were harvested, classified, weighed and yield $\left(\mathrm{kg} \mathrm{ha}^{-1}\right)$ was determined at the end of the experiment. Results of winter crop were greater than those of summer, for yield and tuber classification. Organomineral fertilizer, in the dose $4072.70 \mathrm{~kg} \mathrm{ha}^{-1}$, representing $100 \%$ of the mineral one, increased the yield of tubers Class Special. Winter crop presented good results for soluble solids contents.
\end{abstract}

Keywords: Solanum tuberosum. Nutrition. Bioactivators.

\footnotetext{
*Autor para correspondência

${ }^{1}$ Recebido para publicação em 09/09/2014; aceito em 21/09/2015.

${ }^{2}$ Instituto de Ciências Agrárias, área de Ciência do Solo, UFU, Avenida Amazonas Bloco 4C, 38400-902 Uberlândia (MG); atalitacardoso@yahoo.com.br.

${ }^{3}$ Instituto de Ciências Agrárias, área de Fitotecnia, UFU, Avenida Amazonas Bloco 2E, 38400-902 Uberlândia (MG); jmagno@ufu.br.

${ }^{4}$ Instituto de Ciências Agrárias, área de Ciência do Solo, UFU, Avenida Amazonas Bloco 4C, 38400-902 Uberlândia (MG); rmqlana@ufu.br.
} 


\section{INTRODUÇÃO}

A batata (Solanum tuberosum L.) é tida como importante fonte de alimento para diversas populações do mundo. Trata-se de uma planta herbácea cujo produto comercial são os tubérculos, que são caules modificados que armazenam reservas e necessidade imposta para perpetuação da espécie com fim a suportar o frio em sua região de origem, qual seja: a Cordilheira dos Andes (FERNANDES, 2010; FILGUEIRA, 2008).

No Brasil, a produção de batata em 2013 foi de 3.570 .351 toneladas (aumento de $6 \%$ com relação a 2012) em uma área de 128.432 hectares (IBGE, 2014). De acordo com Miranda et al. (2003), as condições climáticas brasileiras permitem o plantio da batateira todos os meses do ano. Dependendo do clima da região podem ser realizadas três safras distintas: safra das águas (plantio de agosto a novembro); safra da seca (plantio de janeiro a março); e safra de inverno (plantio de maio a julho).

A safra das águas representa mais de $50 \%$ da produção brasileira de tubérculos e se caracteriza pela presença de chuvas e alto custo de produção em função da pressão de doenças. Já na safra de inverno as produtividades são elevadas e se caracteriza por possuir pacote tecnológico superior a produção da safra das águas pela necessidade de irrigação suplementar (CEPEA, 2013).

A maior parte da produção de tubérculos na safra de inverno se concentra em solos de cerrado, no município de Cristalina (GO), responsável por $28,6 \%$ da produção brasileira de tubérculos. Isso gera preocupações quanto a exigência de práticas de correção e fertilização desses solos, assim como sua característica de alta fixação de fósforo $(\mathrm{P})$, magnésio (Mg) e micronutrientes (ARIMURA et, al. 2007).

A presença de componentes orgânicos nos fertilizantes organominerais permite o aumento da retenção de nutrientes no solo devido ao aumento da capacidade de troca de cátions do mesmo. A respectiva característica provoca menor lixiviação de nutrientes no solo e maior aproveitamento dos nutrientes pela planta, uma vez que são mais lentamente disponibilizados. Outras vantagens podem ser também proporcionadas pelo componente orgânico como: melhoria da capacidade do solo de agregação; aumento da capacidade de retenção; complexação de metais pesados; manutenção de equilíbrio do $\mathrm{pH}$; e aumento na aeração do solo e maior favorecimento do crescimento de microrganismos benéficos. (CERRI, 2011).

No manejo da cultura da batata é necessário o uso de doses adequadas de fertilizantes para a obtenção de altas produtividades. É considerada a cultura com maior taxa de aplicação de fertilizantes, supe- rando 5,7 vezes a cultura da soja (ANDA, 2000).

Dentre as cultivares plantadas no país, a cultivar Atlantic se destaca pela alta produtividade de tubérculos, precocidade, alto teor de massa seca e alto teor de sólidos solúveis. Todavia, é a cultivar mais plantada para a produção de "chips" (ABBA, 2013).

Devido a visível conscientização ambiental nos últimos anos e a escassez de matérias-primas para produção de fertilizantes minerais, aumenta a tendência de reaproveitamento de resíduos urbanos, industriais e agrícolas com o intuito de despoluir o ambiente e criar produtos alternativos para uso na agricultura como, por exemplo, os fertilizantes organominerais.

À luz dessas considerações, o objetivo deste trabalho foi avaliar o efeito do uso de fertilizante organomineral em comparação com o fertilizante mineral sobre a produtividade e qualidade de tubérculos de batata em duas safras de plantio.

\section{MATERIAL E MÉTODOS}

Os experimentos foram realizados no município de Cristalina (GO) com a cultivar Atlantic. O município possui altitude em torno de $1189 \mathrm{~m}$, pluviosidade média de $1426,3 \mathrm{~mm}$ e temperatura média de $20,4^{\circ} \mathrm{C}$. Os plantios foram realizados em áreas cedidas pela empresa Agrícola Wehrmann ${ }^{\circledR}$, instalados em 26 de maio de 2012 e 29 de outubro de 2012 , e colhidos em 29 de agosto de 2012 e 16 de fevereiro de 2013, constituindo a safra de inverno e das águas, respectivamente.

A distribuição de precipitação durante o período da condução dos experimentos se encontra na (Tabela 1).

A classe do solo nas duas áreas cultivadas é um Latossolo vermelho distrófico ( $\mathrm{LVd}$ ), com textura argilosa (FERREIRA, 2010a). A análise química do solo realizada na profundidade de $0-20 \mathrm{~cm}$ (DONAGENA et al., 2011) apresentou os seguintes resultados: $\mathrm{P}=50 \mathrm{mg} \mathrm{dm}^{-3} ; \mathrm{K}=161 \mathrm{mg} \mathrm{dm}^{-3} ; \mathrm{pH}$ $=6,4 ; \mathrm{Ca}^{+2}=5,4$ cmolc dm $\mathrm{dm}^{-3} \mathrm{Mg}^{+2}=1,0 \mathrm{cmolc} \mathrm{dm}^{-}$ 3; $\mathrm{Al}=0,0 \mathrm{cmolc} \mathrm{dm}{ }^{-3} ; \mathrm{H}+\mathrm{Al}=2,0 \mathrm{cmolc} \mathrm{dm}^{-3}$; $\mathrm{MO}=3,6 \mathrm{~g} \mathrm{dm}^{-3} ; \mathrm{V}=77 \%$; e $\mathrm{T}=8,8 \mathrm{cmolc} \mathrm{dm}^{-3}$.

$\mathrm{O}$ delineamento experimental foi disposto em blocos ao acaso, com 6 doses e 4 repetições na safra de inverno, e 7 doses e 4 repetições na safra das águas (Tabela 2). Tendo em vista a não existência de diferenças não significativas entre os tratamentos na safra de inverno optou-se por incluir um tratamento testemunha (sem aplicação de fertilizante) no experimento desenvolvido na safra das águas. 
Tabela 1. Distribuição de precipitação de chuvas (P) e temperaturas máximas (Tmáx) e mínimas (Tmin) das safras em estudo.

\begin{tabular}{|c|c|c|c|c|c|c|c|}
\hline \multicolumn{4}{|c|}{ Safra de inverno } & \multicolumn{4}{|c|}{ Safra das águas } \\
\hline & \multirow{2}{*}{$\begin{array}{c}\mathrm{P} \\
\mathrm{mm}\end{array}$} & \multirow[t]{2}{*}{ Tmín } & \multicolumn{2}{|l|}{ Tmáx } & \multirow{2}{*}{$\begin{array}{c}\mathrm{P} \\
\mathrm{mm}\end{array}$} & \multirow[t]{2}{*}{ Tmín } & \multirow[t]{2}{*}{ Tmáx } \\
\hline & & & & & & & \\
\hline Mai & 3,40 & 14,80 & 22,66 & Out & 0,00 & 18,00 & 34,20 \\
\hline Jun & 0,00 & 14,20 & 21,23 & Nov & 2,66 & 19,13 & 27,46 \\
\hline Jul & 0,00 & 13,00 & 24,19 & Dez & 3,10 & 17,90 & 29,77 \\
\hline \multirow[t]{2}{*}{ Ago } & 0,00 & 14,00 & 26,40 & Jan & 5,73 & 19,09 & 27,09 \\
\hline & & & & $\mathrm{Fev}$ & 2,11 & 18,43 & 27,25 \\
\hline
\end{tabular}

Fonte: INMET (2015).

Tabela 2. Tratamentos utilizados nos experimentos Cristalina (GO).

\begin{tabular}{ccc}
\hline Fonte de fertilizante & $\begin{array}{c}\text { Porcentagem correspondente ao } \\
\text { fertilizante mineral }\end{array}$ & $\begin{array}{c}\text { Dose aplicada } \\
\left(\mathrm{kg} \mathrm{ha}^{-1}\right)\end{array}$ \\
\hline Sem adubação & 0,00 \\
Fertilizante mineral & 0,00 & 2800,00 \\
$(3-32-8)$ & & \\
Organomineral & $40 \%$ & 1629,10 \\
Organomineral & $60 \%$ & 2443,60 \\
Organomineral & $80 \%$ & 3258,20 \\
Organomineral & $100 \%$ & 4072,70 \\
Organomineral & $120 \%$ & 4887,30 \\
\hline
\end{tabular}

${ }^{1}$ Este tratamento foi apenas na safra das águas.

O experimento da safra de inverno com total de 24 parcelas, constituídas por 6 linhas, espaçadas $0,8 \mathrm{~m}$ entre linhas, com $10 \mathrm{~m}$ de comprimento, totalizou $48 \mathrm{~m}^{2}$ de área por parcela. As avaliações foram realizadas nas duas linhas centrais que compreendiam a área útil da parcela, desprezando-se duas linhas de cada lado dos blocos e meio metro inicial e final de cada bloco, que eram as bordaduras, totalizando $14,4 \mathrm{~m}^{2}$ de área útil por parcela.

O experimento da safra das águas com 28 parcelas, constituídas por 8 linhas, espaçadas $0,8 \mathrm{~m}$ entre linhas, com $8 \mathrm{~m}$ de comprimento, totalizou $51,2 \mathrm{~m}^{2}$ de área por parcela. As avaliações foram realizadas nas duas linhas centrais que compreendiam a área útil da parcela, desprezando-se duas linhas de cada lado dos blocos e meio metro inicial e final de cada bloco, que eram as bordaduras, totalizando $11 \mathrm{~m}^{2}$ da área útil da parcela.

As doses do fertilizante organomineral foram fixadas de acordo com as recomendações de Souza e Lobato (2004) para o fertilizante mineral.

A fonte de NPK de fertilizante mineral utilizada nos experimentos foi o formulado 3-32-6, com $6,7 \%$ de $\mathrm{N}, 78 \%$ de $\mathrm{P}_{2} \mathrm{O}_{5}$ e $10,3 \%$ de $\mathrm{K}_{2} \mathrm{O}$ utilizando as fontes ureia, superfosfato triplo e cloreto de potássio.

O fertilizante organomineral foi produzido a partir de cama de frango proveniente de granjas da região. A produção desse fertilizante envolveu, inicialmente, a compostagem do resíduo orgânico (cama de frango) por meio de um processo aeróbio de decomposição controlada que durou, em média, 20 dias. Para reduzir o período de compostagem foram utilizados coquetéis de nutrientes e microrganismos (fungos e bactérias) para acelerar o processo de decomposição, obtendo-se, em poucos dias, um composto estabilizado. Após a obtenção do composto foram adicionadas as fontes minerais ureia, superfosfato triplo e cloreto de potássio visando o balanço dos nutrientes, o qual foi feito de acordo com a exigência da cultura e da capacidade do solo de fornecer os nutrientes. Em seguida, o material foi homogeneizado e peletizado (TEIXEIRA, 2013).

Os grânulos do fertilizante organomineral possuíram como característica um grau elevado de dureza $(8 \mathrm{kgf} \mathrm{cm}-2)$ que significa alta resistência a quebra e impedimento da formação de partículas desuniformes. A matéria orgânica exerce a proteção física, forma uma matriz porosa ao redor dos nutrientes e impede o contato direto de nutrientes solúveis com o solo. Como consequência, promove menores perdas por fixação e lixiviação (TEIXEIRA, 2013).

A caracterização química do fertilizante organomineral utilizado nos experimentos é apresentada na Tabela 3. 
Tabela 3. Parâmetros químicos dos fertilizantes organomineral e mineral utilizados.

\begin{tabular}{lcc}
\hline Nutrientes & $\begin{array}{c}\text { Mineral } \\
(3-32-6)\end{array}$ & $\begin{array}{c}\text { Organomineral } \\
(2-22-4)\end{array}$ \\
\hline Cálcio & & $\%$ \\
Enxofre & 2,00 & 1,40 \\
Magnésio & 2,00 & 1,40 \\
Boro & 1,50 & 1,10 \\
Cobre & 0,20 & 0,14 \\
Manganês & 0,10 & 0,07 \\
Zinco & 0,15 & 0,11 \\
\hline
\end{tabular}

O preparo do solo foi realizado de acordo com o recomendado para a cultura da batata, por meio de uma aração seguida de gradagem destorroadora/niveladora e, posteriormente, abertura dos sulcos (FILGUEIRA, 2008).

A adubação foi realizada de forma manual, sendo incorporada com o uso de enxadas. Posteriormente no sulco de plantio, local em que foram plantadas as batatas sementes da cultivar Atlantic do tipo 3 (tubérculos com diâmetro de 30 a $40 \mathrm{~mm}$ ).

No solo, foram aplicados, no sulco de plantio, em todas as parcelas, $30 \mathrm{~kg}$ ha- 1 de uma fonte de macro e micronutrientes composta por $2,7 \%$ de $\mathrm{Ca}$, $8,2 \%$ de S, $12 \%$ de $\mathrm{Zn}$ e $6 \%$ de B, de acordo com a recomendação de Souza e Lobato (2013) para a cultura da batata.

Nas duas épocas de plantio, cerca de 30 dias após o plantio, foi feita a amontoa para estimular a tuberização das plantas. Na safra de inverno foi realizada juntamente com a amontoa a adubação de cobertura com $300 \mathrm{~kg}$ ha-1 do formulado 20-00-20, justificada pela baixa precipitação ocorrida no período. O fósforo é absorvido pelas plantas pelo processo de difusão que é controlado pelo conteúdo volumétrico do solo. Na presença da água, esta reage no solo liberando grandes quantidades na forma solúvel, a qual é a assimilável pelas plantas (NOVAIS; SMYTH, 1999). A não realização da adubação de cobertura na safra das águas teve o intuito de verificar o efeito da liberação lenta do fertilizante organomineral.

O sistema de irrigação empregado foi o de pivô central. As plantas receberam aproximadamente $500 \mathrm{~mm}$ de água durante o ciclo, ficando próximo do volume de água indicado para cultura, que varia de 450 a $550 \mathrm{~mm}$.

Após a colheita, os tubérculos foram pesados e classificados e estimada a produtividade e rendimento das classes em t ha ${ }^{-1}$. A classificação foi feita de acordo com o diâmetro dos tubérculos e nas classes Especial (42-70mm), Primeira (33-42mm), Segunda (28-33mm), Diversa (até 28mm), Boneca (tubérculos com algum distúrbio fisiológico) e descarte (tubérculos danificados, não comerciais). $\mathrm{O}$ padrão para classificação utilizado foi o empregado pelas indústrias processadoras de batata (FAEP; 2015):

O teor de sólidos solúveis foi determinado por meio da técnica do densímetro, a qual consiste em retirar uma amostra de $3,63 \mathrm{~kg}$ de tubérculos em cada parcela. Essas amostras foram imersas em um tanque com capacidade de 100 litros de água, no qual aferiu-se a massa submersa de tubérculos. A partir de estimativas fora obtido a massa específica de cada amostra relacionada com o teor de sólidos solúveis expressos em porcentagem.

Os dados foram submetidos a análise de variância. Para a comparação das médias do tratamento do fertilizante mineral e dos tratamentos com o fertilizante organomineral fora aplicado o teste de Dunnett, a 5\% de significância, com o programa SPSS for Windows Release 8.0 (1998). Os dados obtidos dos tratamentos com fertilizante organomineral foram submetidos a análise de regressão polinomial com o programa estatístico SISVAR (FERREIRA, 2000b).

\section{RESULTADOS E DISCUSSÃO}

O plantio na safra de inverno superou em $57 \%$ a safra das águas na produtividade de tubérculos (Tabelas 4 e 5).

$\mathrm{O}$ diferencial de produtividade entre as safras avaliadas pode ser explicado pelo efeito depreciativo das altas temperaturas na produtividade de tubérculos ocorrido na safra das águas. A ocorrência de temperaturas noturnas mais elevadas nesta safra aumenta a respiração com consequente redução na produção, além da pressão de doenças ser maior devido a ocorrência de chuvas. A batateira é uma planta exigente em frio, principalmente a noite. O acúmulo de reservas no tubérculo decorre em função da quantidade de energia que a planta assimila durante o dia, menos o que ela respira. Quanto mais a planta acumular durante o dia, como resultado da fotossíntese, e quanto menos ela respirar maior será o acúmulo de reservas. A temperatura fria a noite colabora para que a planta reduza a respiração e assim acumule mais reserva (WREGE et al., 2005). 
A. F. CARDOSO et al.

Tabela 4. Produtividade $\left(\mathrm{t} \mathrm{ha}^{-1}\right)$ para diferentes classes de tubérculos na safra de inverno em Cristalina (GO).

\begin{tabular}{|c|c|c|c|c|c|c|}
\hline $\begin{array}{c}\text { Doses } \\
\left(\mathrm{kg} \mathrm{ha}^{-1}\right)\end{array}$ & Produtividade & Especial & Segunda & Diversa & Boneca & Descarte \\
\hline & \multicolumn{6}{|c|}{$\mathrm{tha}^{-1}$} \\
\hline \multicolumn{7}{|l|}{ Mineral } \\
\hline 2800,00 & 51,62 & 38,15 & 8,00 & 3,46 & 1,04 & 0,95 \\
\hline \multicolumn{7}{|l|}{ Organomineral } \\
\hline $1629,10(40 \%)$ & 51,62 & $35,00^{*}$ & $11,20^{*}$ & 4,53 & $0,94^{*}$ & 1,00 \\
\hline $2443,60(60 \%)$ & 50,82 & $39,34^{*}$ & $7,30^{*}$ & 1,51 & $0,92^{*}$ & 0,96 \\
\hline $3258,20(80 \%)$ & 50,77 & 41,09 & $6,57^{*}$ & 1,52 & 0,70 & 0,93 \\
\hline $4072,70(100 \%)$ & 52,55 & $43,55^{*}$ & $6,90^{*}$ & 1,48 & $0,93^{*}$ & 0,98 \\
\hline $4887,30(120 \%)$ & 51,62 & $38,50^{*}$ & 9,13 & 2,00 & $1,20^{*}$ & 0,96 \\
\hline
\end{tabular}

${ }^{*}$ Médias diferem do tratamento com fertilizante mineral pelo teste de Dunnett, a 0,05 de significância.

Tabela 5. Produtividade em $\mathrm{t} \mathrm{ha}^{-1}$ para diferentes classes de tubérculos na safra das águas em Cristalina (GO).

\begin{tabular}{ccccccc}
\hline $\begin{array}{c}\text { Doses } \\
\left(\mathrm{kg} \mathrm{ha}^{-1}\right)\end{array}$ & $\begin{array}{c}\text { Produtividade } \\
\text { total }\end{array}$ & Especial & Segunda & Diversa & Boneca & Descarte \\
\hline Mineral & \multicolumn{7}{c}{$\mathrm{t} \mathrm{ha}^{-1}$} \\
\hline 2800,00 & 22,46 & 18,07 & 0,95 & 0,12 & 0,01 & 3,32 \\
\hline Organomineral & & & & & \\
\hline 0,00 & $15,10^{*}$ & $14,06^{*}$ & $0,02^{*}$ & $0,02^{*}$ & 0,01 & $1,07^{*}$ \\
$1629,10(40 \%)$ & $25,60^{*}$ & 22,46 & $1,02^{*}$ & $0,23^{*}$ & 0,00 & $2,15^{*}$ \\
$2443,60(60 \%)$ & $31,40^{*}$ & 26,53 & $1,23^{*}$ & $0,33^{*}$ & 0,00 & $3,23^{*}$ \\
$3258,20(80 \%)$ & $35,18^{*}$ & 28,36 & $2,32^{*}$ & $0,37^{*}$ & 0,18 & $3,91^{*}$ \\
$4072,70(100 \%)$ & $42,55^{*}$ & $38,04^{*}$ & $2,41^{*}$ & $0,38^{*}$ & 0,00 & $1,54^{*}$ \\
$4887,30(120 \%)$ & $28,40^{*}$ & 26,04 & $1,22^{*}$ & $0,42^{*}$ & 0,00 & $1,82^{*}$ \\
\hline
\end{tabular}

*Médias diferem do tratamento com fertilizante mineral pelo teste de Dunnett, a 0,05 de significância.

Outro fator preponderante na produção de tubérculos é a intensidade luminosa. Na presença de alta intensidade de luz, a assimilação das plantas é mais elevada que em condições de intensidade reduzida. Quando a intensidade luminosa aumenta a temperatura ótima para assimilação das plantas também se torna ligeiramente mais alta. Portanto, regiões muito ensolaradas são mais favoráveis que as frequentemente nubladas. A presença de muita luz modifica a relação folhagem/crescimento dos tubérculos em favor do crescimento destes. Isso explica o motivo pelo qual é possível a obtenção de elevadas produtividades em plantios em regiões de altitude e alta intensidade de luz, como o município de Cristalina, em que a intensidade da luz é elevada, mesmo com temperaturas diurnas mais elevadas e temperaturas mais baixas durante a noite. As maiores produtividades são obtidas nos países onde os dias duram de 13 a 17 horas na época de tuberização, com temperaturas médias entre 15 e $18^{\circ} \mathrm{C}$ e com irrigação (HAEDER; BERINGER, 1983).

$\mathrm{Na}$ safra de inverno não foram observadas diferenças entre os tratamentos em que se utilizou o fertilizante mineral e as doses do organomineral para produtividade de tubérculos. Vale ressaltar que os resultados obtidos para a produtividade foram superiores à média brasileira, que é de 27,80 t ha-1, segundo dados do IBGE (2014). Diferentes resultados para a mesma cultivar utilizada no presente trabalho e uso de fertilizantes minerais foram encontrados por outros autores. Fernandes et al. (2010), na safra de inverno, em Itaí (SP), obteve uma produtividade de 22 t ha-1. Já Yorinori (2003) observou produtividade de 24 t ha-1 na safra da seca e 36,5 $\mathrm{t} \mathrm{ha}^{-1}$ na safra das águas.

Na comparação dos valores obtidos na dose do fertilizante mineral em relação a dose em que se utilizou $100 \%$ na fonte organomineral observou-se um incremento de $13 \%$ no rendimento de tubérculos para a classe Especial. É importante salientar que se trata de uma classe almejada na produção dos tubérculos por se caracterizar pela produção de tubérculos com diâmetro maior que $42 \mathrm{~mm}$ (PEREIRA; CAMPOS, 1999).

Para a safra das águas verificou-se, com exceção da testemunha, que todas as doses em que se utilizaram o fertilizante organomineral foram superiores a mineral para a produtividade de tubérculos. Nota-se, também, um crescente aumento de produtividade até a dose em que se utilizou $100 \%$ na fonte organomineral. A utilização de doses elevadas de fertilizantes, como os fosfatados em altas doses, podem causar interações antagonistas com outros nutrientes e limitar a produtividade na cultura da batata (FERNANDES; SORATTO, 2012).

$\mathrm{Na}$ classificação dos tubérculos, para a dose de $100 \%$ na fonte organomineral, observou-se um aumento de $39 \%$ e redução de $79 \%$ no rendimento de tubérculos das classes Especial e Descarte, respectivamente, em relação ao fertilizante mineral. Esses resultados provavelmente estão relacionados a fonte de fertilizante organomineral que apresenta 
solubilização gradativa no decorrer do período de desenvolvimento da cultura, o que torna a eficiência agronômica maior quando comparado com os fertilizantes convencionais (KIEHL, 2008).

Foi observado ajuste quadrático significativo para a produtividade total dos tubérculos na avaliação das doses. Para a dose de fertilizante organomineral $2997,50 \mathrm{~kg}$ ha-1 fora estimado uma produtividade total máxima de 31,31 t ha-1 (Figura 1).

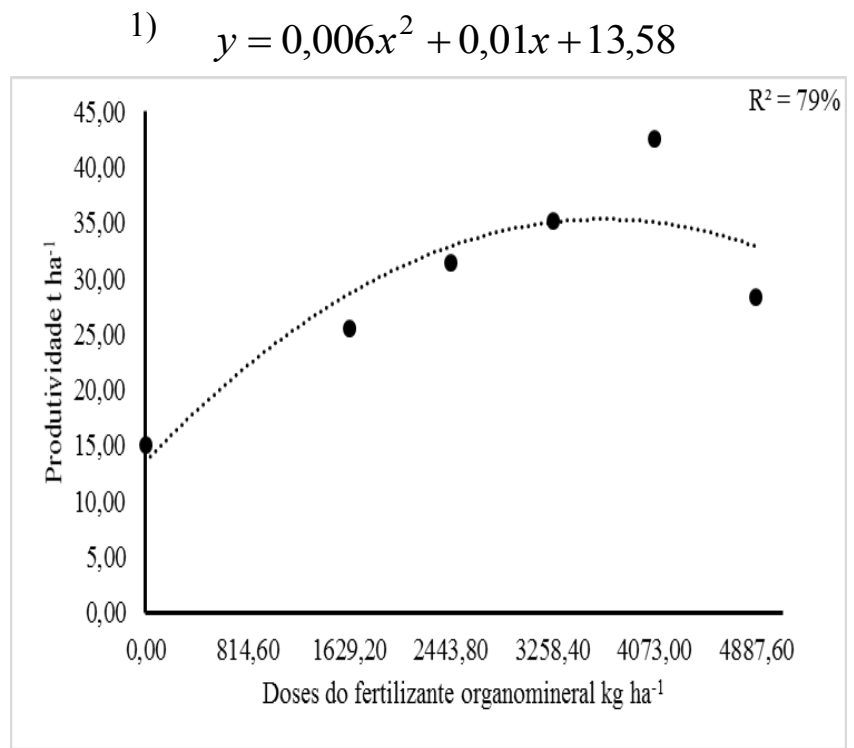

Figura 1. Produtividade total de tubérculos em função das doses do fertilizante organomineral na safra das águas.

$\mathrm{Na}$ classificação de tubérculos em Especial foi observado ajuste quadrático significativo nas duas safras avaliadas (Figura 2). Para a safra de inverno constatou-se rendimento máximo de 47,90 t ha-1 para a dose de $3529,00 \mathrm{~kg}$ ha-1 de organomineral, a qual representa $86,65 \%$ da dose de fertilizante mineral. Na safra das águas foi verificado na dose de $3500,00 \mathrm{~kg}$ ha-1 de organomineral rendimento máximo estimado de 27,00 t ha-1, correspondendo a $85,90 \%$ da dose do fertilizante organomineral. Para as duas safras, pode-se notar que o pico de rendimento ocorreu em torno de $86 \%$ da dose de organomineral. A partir desta dose não houve resposta positiva ao rendimento de tubérculos.

$$
2 y=-0,006 x^{2}+0,028 x-1,8
$$

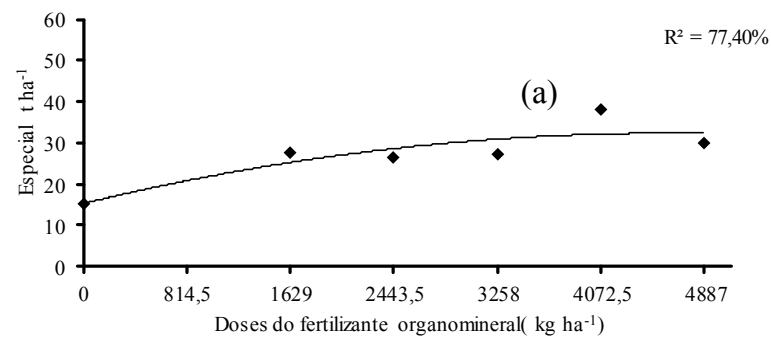

$$
3 y=0,00000007 x^{2}+0,007 x+15,28
$$

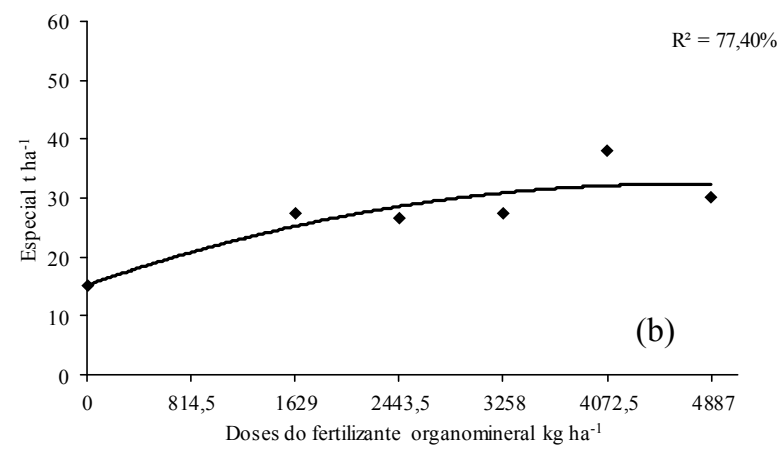

Figura 2. Produtividade de tubérculos de batata da classe Especial da cultivar Atlantic em função das doses do fertilizante organomineral no sulco de plantio nas safras de inverno (a) e das águas (b). 
Para a classe Segunda foi observado ajuste quadrático de regressão para a safra das águas (Figura 3). Na dose $3571,42 \mathrm{~kg}$ ha-1 do fertilizante organomineral foi obtida uma produtividade máxima estimada de 1,63 t ha-1. As condições climáticas dessa safra parecem ter induzido um maior gasto do fertilizante para essa classe, que apresentou uma produtividade baixa em relação a produtividade total de tubérculos.

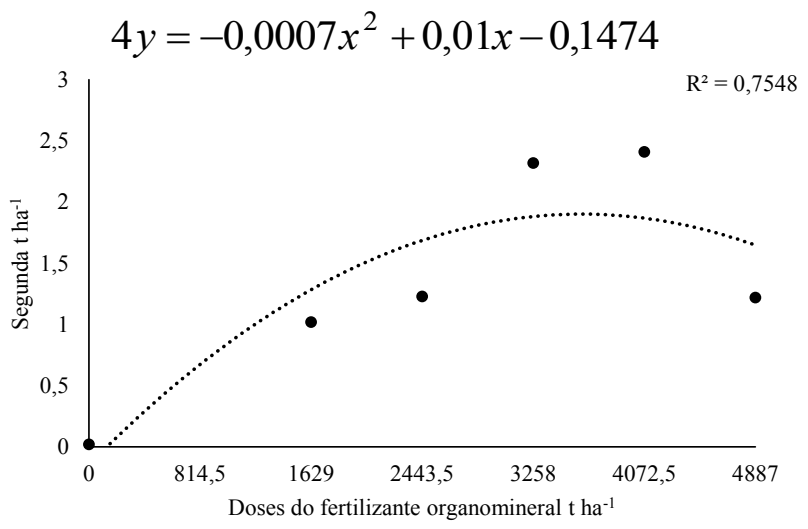

Figura 3. Produtividade de tubérculos de batata da classe Segunda da cultivar Atlantic em função das doses do fertilizante organomineral no sulco de plantio na safra das águas.

Na safra de inverno, verificou-se aumento na produção de tubérculos com as crescentes doses do fertilizante organomineral. A classe Boneca é consi-

$$
5 y=0,07 x^{2}-0,0007 x+1,75
$$

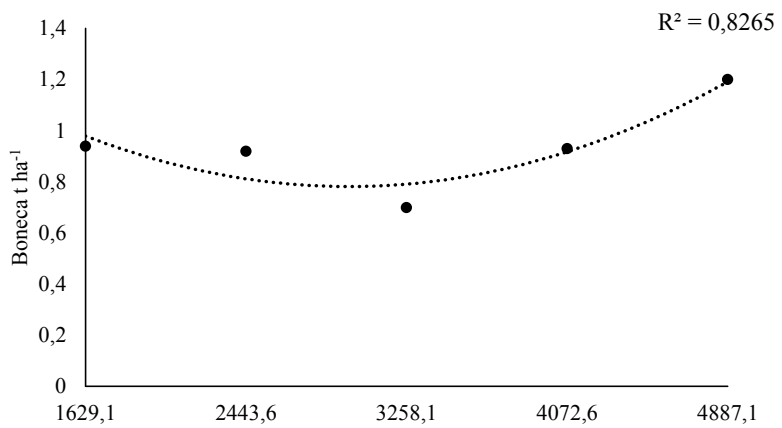

Figura 4. Produtividade de tubérculos de batata da classe Boneca em função das doses do fertilizante organomineral no sulco de plantio na safra de inverno.

A classificação de tubérculos em Descarte apresentou significância $(\mathrm{P}<0,01)$ e o modelo de regressão quadrático se ajustou melhor para a safra das águas (Figura 5). Observou-se que a produtividade, na classe Descarte, dose de 2551,01 kg ha-1, derada uma classe não comercial e não requerida pelos produtores (Figura 4).

$$
6 y=-0,00007 x^{2}+0,0016+0,9361
$$

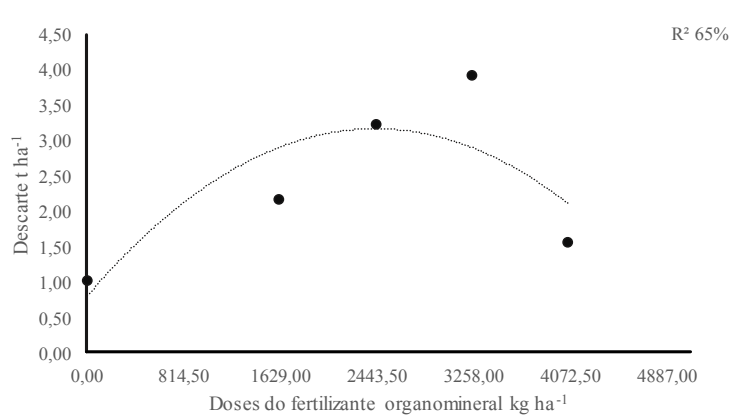

Figura 5. Produtividade de tubérculos de batata da classe Descarte em função das doses do fertilizante organomineral no sulco de plantio na safra das águas. 
Os sólidos solúveis são utilizados como uma medida indireta do teor de açúcares (SS) dissolvidos nos tubérculos. Em relação aos teores de sólidos solúveis nos tubérculos para a safra de inverno observasse que apenas a dose de $1649,10 \mathrm{~kg}$ ha-1 (40\% do fertilizante organomineral) se diferenciou da maior dose 4887,30 kg ha-1 (120\%), com uma diferença de 6\% (Tabela 6). De acordo com Grizottto (2005), o tubérculo destinado à indústria, como os da cultivar Atlantic, é desejável que apresente teor de sólidos solúveis acima de 18\% para obtenção de chips de qualidade, o que ocorreu nessa safra.

Os teores de sólidos solúveis foram maiores na safra de inverno em relação a safra das águas. Essa redução na safra das águas provavelmente pode estar relacionada ao efeito das altas temperaturas observadas nos meses de outubro, novembro e dezembro (Tabela 1), as quais proporcionaram aumento no metabolismo e consumo dos carboidratos disponíveis pelos órgãos das plantas, tendo como resultado um menor acúmulo de açúcares em relação a safra de inverno (SALISBURY; ROSS, 1992).
Para a safra das águas, de acordo com os resultados do presente estudo, a adubação com fertilizante mineral, quando comparada com a dose $4072,70 \mathrm{~kg}$ ha-1 (100\%), foi estatisticamente inferior, com uma diferença de 14\%. Para Lopes (1995), o potássio é o nutriente capaz de influenciar o aumento dos teores de sólidos solúveis nos vegetais. A associação da fração orgânica dos fertilizantes organominerais com a do potássio mineral melhora a eficiência do fertilizante, haja vista que os cátions $\mathrm{K}^{+}$podem se ligar eletrostaticamente com as cargas negativas do molibdênio, ficando por mais tempo disponível às raízes e resistindo mais à lixiviação pela água das chuvas (KIELH, 2008).

Resultados diferentes para a mesma cultivar do presente estudo foram reportados por Ferreira et al. (2009), os quais avaliaram a produtividade e a qualidade de tubérculos da cultivar Atlantic em função das épocas de aplicação de silicato, verificando valores de $17,72 \%$ de sólidos solúveis. Gonçalves (2009) na avaliação de doses de silicato de potássio verificou um teor de sólidos solúveis $17,5 \%$ nos tubérculos.

Tabela 6. Teor de sólidos solúveis (SS) para diferentes doses de fertilizante organomineral e fertilizante mineral na safra de inverno e das águas, Uberlândia, 2014.

\begin{tabular}{ccc}
\hline & Safra de inverno & Safra das águas \\
\hline Doses $\left(\mathrm{kg} \mathrm{ha}^{-1}\right)$ & \multicolumn{2}{c}{ SS (\%) } \\
\hline 2800,00 & $18,60 \mathrm{ab}$ & $14,82 \mathrm{~b}$ \\
Testemunha & & $15,55 \mathrm{ab}$ \\
$1629,10(40 \%)$ & $19,45 \mathrm{a}$ & $16,50 \mathrm{ab}$ \\
$2443,60(60 \%)$ & $18,85 \mathrm{ab}$ & $16,00 \mathrm{ab}$ \\
$3258,20(80 \%)$ & $18,42 \mathrm{~b}$ & $16,15 \mathrm{ab}$ \\
$4072,70(100 \%)$ & $18,82 \mathrm{ab}$ & $16,90 \mathrm{a}$ \\
$4887,30(120 \%)$ & $18,45 \mathrm{~b}$ & $16,57 \mathrm{ab}$ \\
\hline $\mathrm{cv} \%$ & 2,81 & 5,34
\end{tabular}

\section{CONCLUSÕES}

O plantio da cultura da batata deve ser realizado, preferencialmente, no período do inverno e/ou em regiões que apresentem alta altitude para compensar os efeitos causados por altas temperaturas.

Conclui-se, para a produtividade e classificação dos tubérculos, que a safra de inverno apresentou maior produtividade, melhores resultados na classificação dos tubérculos e valores satisfatórios para o teor de sólidos solúveis.

A dose de $4072,70 \mathrm{~kg} \mathrm{ha}^{-1}$ do fertilizante organomineral que corresponde a $100 \%$ da dose mineral proporcionou maior produtividade e rendimento de tubérculos na classe Especial.
TA. Variedades. Disponível em: $<\mathrm{http}: / /$ www.abbabatatabrasileira.com.br/2008/ variedades.asp>. Acesso em: 16 dez. 2013.

ANDA - ASSOCIAÇ̃̃O NACIONAL PARA DIFUSÃO DOS ADUBOS. Anuário Estatístico. São Paulo, SP: ANDA, 2000. 252 p.

ARIMURA et al. Influência da aplicação de produtos organominerais Aminoagro na produção de batata, cv. Ágata. In: ENCONTRO NACIONAL DA PRODUÇÃ̃O E ABASTECIMENTO DE BATATA. Holambra, 13, 2013, Holambra. Anais eletrônicos... Holambra: ABBA, 2003. Disponível em: http:// www.abbabatatabrasileira.com.br/batatashow4/ resumos/resumo_30.pdf. Acesso em: 04 abr. 2013.

\section{REFERÊNCIAS}

ABBA - ASSOCIAÇÃO BRASILEIRA DA BATA-
Centro de Estudos Avançados em Economia Aplicada (CEPEA). Indicadores do preço da batata. 2013. Disponível em: http://cepea.esalq.usp.br/ hfbrasil/edicoes/126/batata.pdf. Acesso em: 04. 
mar.2013.

CERRI, C. E. Eficiência agronômica dos organominerais: Informe Abisolo. 1. ed. São Paulo, SP: ABISOLO, 2011. $10 \mathrm{p}$.

DONAGEMA, G. K. et al. Manual de métodos de análise de solos. 2. ed. Rio de Janeiro, RJ: EMBRAPA SOLOS, 2011. 230 p.

FAEP. Federação de Agricultura do Estado do Paraná. Classificação de tubérculos para cultivares de batata. Disponível em: http://www.faep.com.br/ comissoes/frutas/cartilhas/hortalicas/batata.htm.

Acesso em: 03 mai. 2015.

FERNANDES, A. M. et al. Crescimento, acúmulo e distribuição de matéria seca em cultivares de batata na safra de inverno. Pesquisa Agropecuária Brasileira, Brasília, v. 45, n. 8, p. 826-835, 2010.

FERNANDES, A. M.; SORATTO, R. P. 2012. Nutrition, dry matter accumulation and partitioning and phosphorus use efficiency of potato grown at different phosphorus levels in nutrient solution. Revista Brasileira de Ciência do Solo, Viçosa, v. 36, n. 2, p. 1528-1537, 2012.

FERREIRA, D. F. a. SISVAR: Sistema de análise de variância. Versão 5.3. Lavras-MG: Lavras-MG: UFLA, 2010.

Ferreira, M. M. Caracterização física do solo. In: Lier, Q. J. van (ed.). Física do solo. Viçosa: Sociedade Brasileira de Ciência do Solo, v.1, cap.1, p.127.

FERREIRA, P. G. et al. Produtividade e qualidade de tubérculos de batata, cv. Atlantic, em função de épocas de aplicação de silicato de potássio. Horticultura Brasileira, Brasília, v. 27, n. 2, p. 30483052, ago. 2009.

FILGUEIRA, F. A. R. Novo Manual de Olericultura: agrotecnologia moderna na produção e comercialização de hortaliças. 3. ed: Viçosa: UFV, 2008, 412 p.

GONÇALVES, M. V. Arquitetura de planta, teor de clorofila e produtividade da batata Atlantic, sob doses de silicato de potássio via foliar. 2009. 51 f. Dissertação (Mestrado em Agronomia: Área de Concentração em Fitotecnia) - Universidade Federal de Uberlândia, Uberlândia, 2009.

GRIZOTTO, R.K. Processamento e rendimento industrial de batata chips e palha. Seminário brasileiro sobre processamento de batatas, Pouso Alegre. 2005. Disponível em: http:// www.abbabatatabrasileira.com.br/minas2005/19\%
$20 \% 20$ Processamento $\% 20 \mathrm{da} \% 20$ batata $\% 20$ chips $\%$ 20e\%20palha\%2001.pdf. Acesso em: 01 abr 2014.

HAEDER, H. E., BERINGER, H. Potencial productvity of field crops under diferente envirimments. 1. ed. Philippines: IRRI, 1983, v.1, 534 p. IBGE. INSTITUTO BRASILEIRO DE GEOGRAFIA E ESTATÍSTICA - Produção agrícola municipal em 2013. Disponível em: <http:// www.ibge.gov.br/home/estatistica/indicadores/ agropecuaria/lspa/lspa_201404_5.shtm $>$. Acesso em: 04 abr. 2014.

INMET. Instituto Nacional de Meteorologia 2015. Dados históricos meteorológicos 2012 e 2013. Disponível em: http://www.inmet.gov.br/portal/ index.php? $\mathrm{r}=\mathrm{bdmep} / \mathrm{bdmep}$. Acesso em: 08 jun. 2015.

KIEHL, E. J. Fertilizantes organominerais. 4. ed. Piracicaba, SP: DEGASPARI, 2008. 160 p.

LOPES, A. S. Manual internacional de fertilidade do solo. 1. ed. Piracicaba, SP: POTAFOS, 1995, $177 \mathrm{p}$.

MIRANDA FILHO, H. S. da; GRANJA, N.P.do; MELO, P.C.T. de. Cultura da batata. 1. ed. Vargem Grande do Sul, SP: FAEF, 2003, 68 p.

NOVAIS, R. F.; SMYTH, T. J. Fósforo em solo e planta em condições tropicais. 2. ed. Viçosa, MG: Universidade Federal de Viçosa, 1999. 399 p

SALISBURY, F. B.; ROSS, C. W. Plant Physiology. 4. ed. Belmont, CA: Wadsworth Publishing Company, 1992. 682 p.

SOUSA, D. G.; LOBATO, E. Cerrado: correção do solo e adubação. 2 ed. Planaltina, DF: EMBRAPA Cerrados, 2004. 416 p.

SPSS Inc. SPSS Base 8.0 for Windows User's Guide and SPSS Interactive Graphics 8.0. 8.ed. Chicago, IL: SPSS Inc; 1999. 640 p.

PEREIRA, A.S.; CAMPOS, A. Teor de açúcares em genótipo de batata (Solanum tuberosum L.). Ciência Rural, Santa Maria, v. 29, n. 9, p. 13-16, 1999.

YORINORI, G.T. Curva de crescimento e acúmulo de nutrientes para a cultura da batata cv. Atlantic. 2003. 79 f. Dissertação (Mestrado em Agronomia) - Escola Superior de Agricultura "Luiz de Queiroz"- Universidade de São Paulo, Piracicaba, 2003.

WREGE, M.S.; PEREIRA, A. da S.; HERTER, F.G. Climas das principais regiões produtoras de batata do Brasil. Batata Show: A revista da batata, Itappeti- 
ninga-SP, n.11, 2005. Disponível em: http: www.abbabatatabrasileira.com.br/ revista11_026.htm>. Acesso em: 30 maio.2014. 